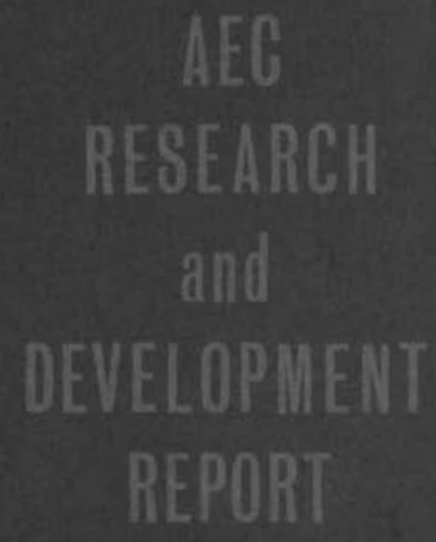

\title{
WASHOUT TESTING OF MIXED OXIDE CERAMIC CORE FUEL ELEMENTS
}

K. D. HAYDEN

OCTOBER, 1966

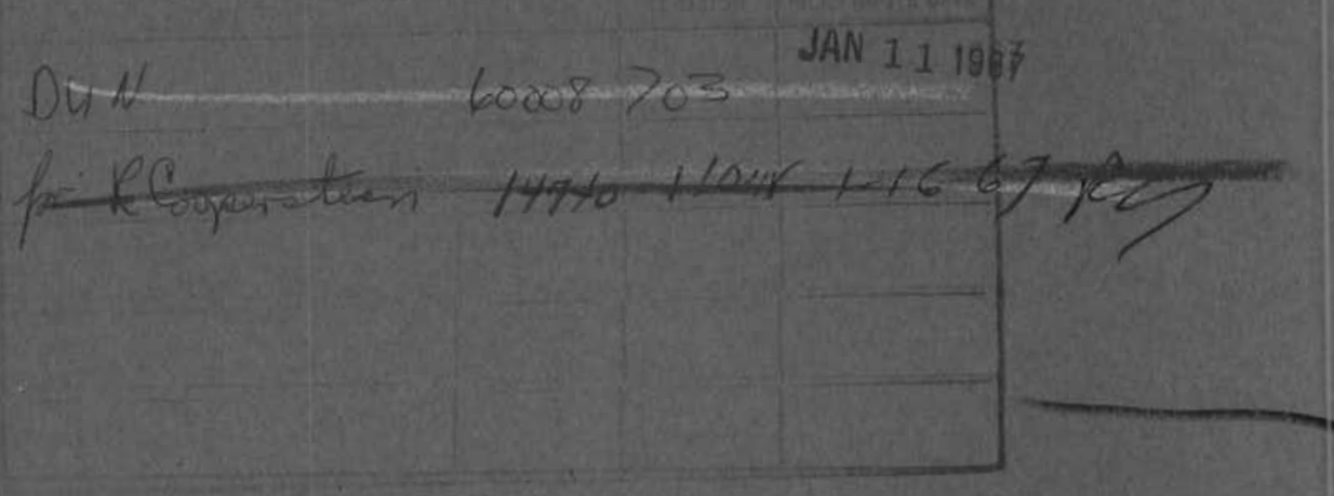

BATTELLE-NORTHWEST

BATTELLE MEMORIAL INSTITUTE / PACIFIC NORTHWEST LABORATORY 


\section{LEGAL NOTICE}

This report was prepared as an account of Government sponsored work. Neither the United States, nor the Commission, nor any person acting on behalf of the Commission:

A. Makes any warranty or representation, expressed or implied, with respect to the accuracy, completeness, or usefulness of the information contained in this report, or that the use of ony information, apparatus, method, or process disclosed in this report may not infringe privately owned rights; or

B. Assumes any liabilities with respect to the use of, or for damages resulting from the use of any information, apparatus, method, or process disclosed in this report.

As used in the above, "person acting on behalf of the Commission" includes any employee or contractor of the Commission, or employee of such confractor, to the extent that such employee or contractor of the Commission, or employee of such contractor prepares, disseminates, or provides access to, any information pursuant to his employment or contract with the Commission, or his employment with such contractor.

PACIFIC NORTHWEST LABORATORY

RICHLAND, WASHINGTON

operated by

BATTELLE MEMORIAL INSTITUTE

for the

UNITED STATES ATOMIC ENERGY COMMISSION UNDER CONTRACT AT(45-1)-1830 


\title{
33679000602872
}

\author{
BNWL - 295 \\ UC-25, Metals, \\ Ceramics and Materials
}

\section{WASHOUT TESTING OF MIXED OXIDE CERAMIC CORE FUEL ELEMENTS}

by

\author{
K. D. Hayden \\ Reactor Engineering Section \\ Reactor and Materials Technology Department
}

October 1966

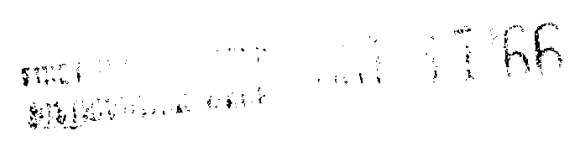

PACIFIC NORTHWEST LABORATORY

RICHLAND, WASHINGTON 
Printed in USA. Price $\$ 1.00$. Available from the Clearinghouse for Federal Scientific and Technical Information National Bureau of Standards

U. S. Department of Commerce

Springfield, Virginia 


\author{
WASHOUT TESTING OF MIXED OXIDE \\ CERAMIC CORE FUEL ELEMENTS
}

\section{INTRODUCTION}

This report describes the tests that were run in an out-of-reactor loop to determine if some fuels were better than others in resisting core washout. In most cases the fuel material had been previously irradiated in the PRTR.

Fuel elements presently used in the Plutonium Recycle Test Reactor (PRTR) consist almost entirely of $\mathrm{UO}_{2}$ or mixed $\mathrm{UO}_{2}-\mathrm{PuO}_{2}$ cores with Zircaloy-2 cladding. Many different fabrication techniques and starting core material have been used in the manufacture of these fuel elements. Besides the differences in percentage of $\mathrm{PuO}_{2}$ $(0 \%, 0.48 \mathrm{wt} \%, 0.75 \mathrm{wt}, 1.0 \mathrm{wt} \%, 2.0 \mathrm{wt} \%$ and $4.0 \mathrm{wt} \%$ ) in the core, the core material can be processed either by sintering or arc fusing, and then prepared by physically mixing or by pneumatically-mechanically impacting particles ("Nupac" process). Finally, the core material can be brought to a high density within the cladding either by swaging, impacting, or vibrational compacting ("Vipac" process).

\section{SUMMARY}

The washout of core material following a fuel element failure was evaluated in the Irradiated Rupture Prototype (IRP) Loop. The irradiated elements were defected with a long slit and placed in a shielded test section which was connected directly to the loop. The water in the loop was then heated, and the test was run for several weeks. The release of core material was determined by weighing the fuel element, by visual inspection, and by continuous measurements of activity levels in different portions of the loop.

The five ceramic core fuel rods tested in the IRP were selected to compare different fabrication procedures and core material with the amount of core washout. The first fuel element was fabricated by physical mixture Vipac process, and released $1 \mathrm{~g}$ of core material. The second fuel element, with a physical mixture-swaged core, had no core washout, while the third fuel rod, prepared by the Nupac-Vipac process, released $7 \mathrm{~g}$ of core, primarily during thermal cycling. A fourth Nupac-swaged rod lost core material only after external vibration was applied to the test section. A fifth rod tested had an unirradiated core, typical of a PRTR short core element, fabricated by Vipac-Nupac, and it lost a total of $84 \mathrm{~g}$ during 24 days of testing. From the tests, it was observed that

- Swaged elements tend to be more resistant to washout than Vipac elements

- The amount of core material washed out depends on the amount of vibration present

- In general, core washout without externally applied vibration tends to be small even with large defects in the cladding. 


\section{DISCUSSION}

\section{DESCRIPTION OF EQUIPMENT}

The tests were performed in the Irradiated Rupture Prototype (IRP), an out-of-reactor recirculating water loop. (1) A schematic diagram of the loop is shown in Figure 1. A fullflow filter with a $2 \mu$ pore size retained the bulk of the washed out core material. With the use of radiation instruments, the filter was also used as a monitoring location for following the rate and amount of core release. The fuel rods to be tested were loaded into a cask under water, and the cask was used as the test section for the loop by connecting it directly to the loop. The cask was oriented vertically when attached to the IRP rather than horizontally as it is in Figure 1. Operating conditions of the loop were $315{ }^{\circ} \mathrm{C}, 1700$ psi and with a maximum flow rate of $30 \mathrm{gpm}$. The loop proper was enclosed in a 1 foot thick concrete shielding wall with the instrument panel located outside of the enclosure.

\section{MATERIALS}

The fuel pieces for these tests were individual sections of Zircaloy-2 clad rods of about 0.57 in. OD, 12 in.

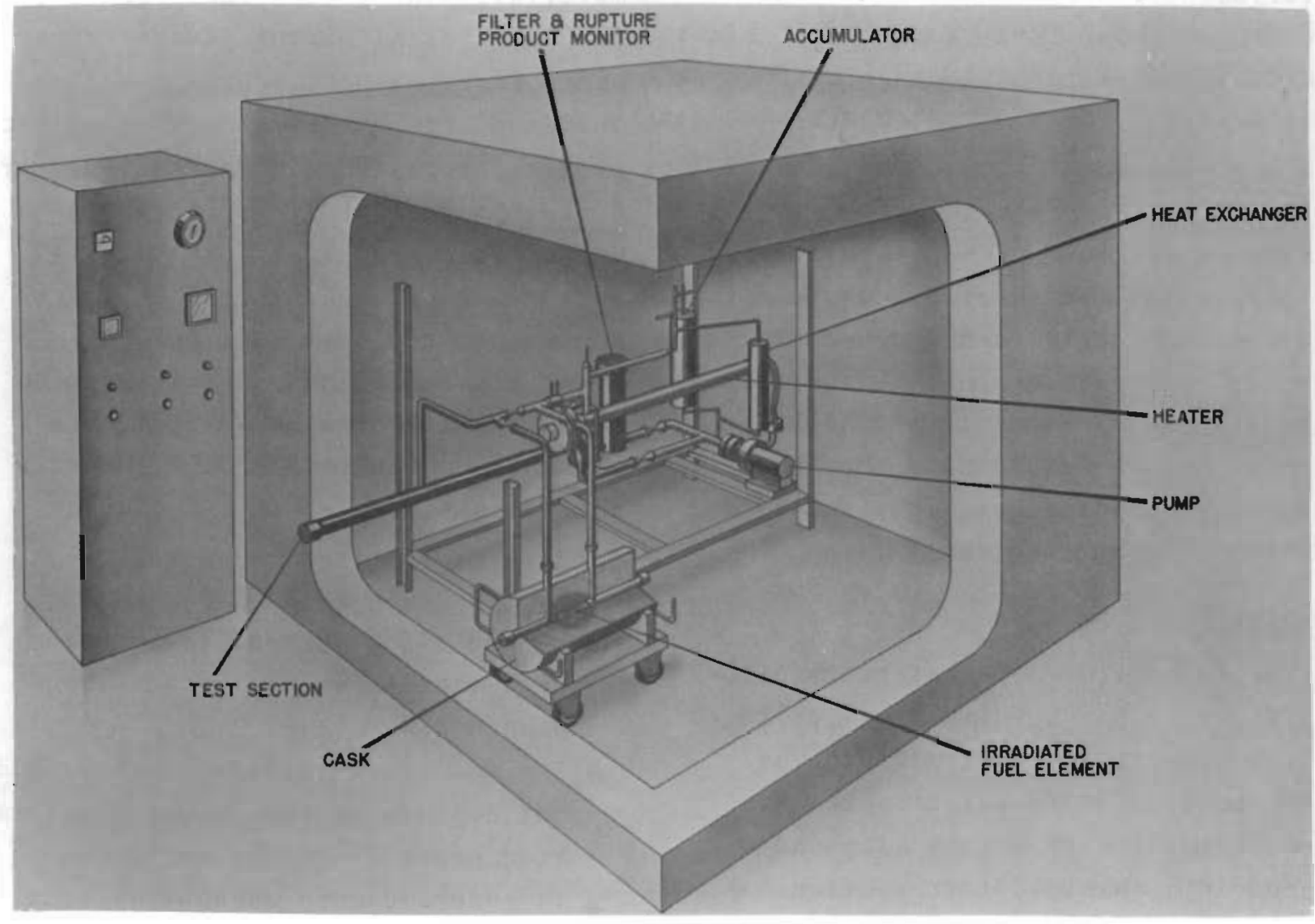

FIGURE 1. Irradiated Rupture Prototype 
long, and with clad thicknesses of 0.030 in. Four of the rods were from 19-rod cluster elements fabricated by Ceramics Research and Development for use in the PRTR. After irradiation in PRTR, the elements or individual rods were sent to Radiometallurgy, where a 12 in. section was cut from the rod for IRP testing. The core material in the ends of the rods were removed and a "Lee" type mechanical seal (Figure 2) was used to cap the ends and to provide a centering device for the rod when in the test cask. The elements were defected with a slit in the cladding down to the core. Usually, the slit was $6 \mathrm{in.}$ long by $1 / 16 \mathrm{in.}$ wide. The first test used a slit only $11 / 2$ in. long, but it was later increased to 6 in. The remaining rod tested was unirradiated, but was of the same size and had the same defect geometry.

The first two tests were made with fuel rods exposed to 5000 and 4100 MWd/ton, with mixed oxide cores of
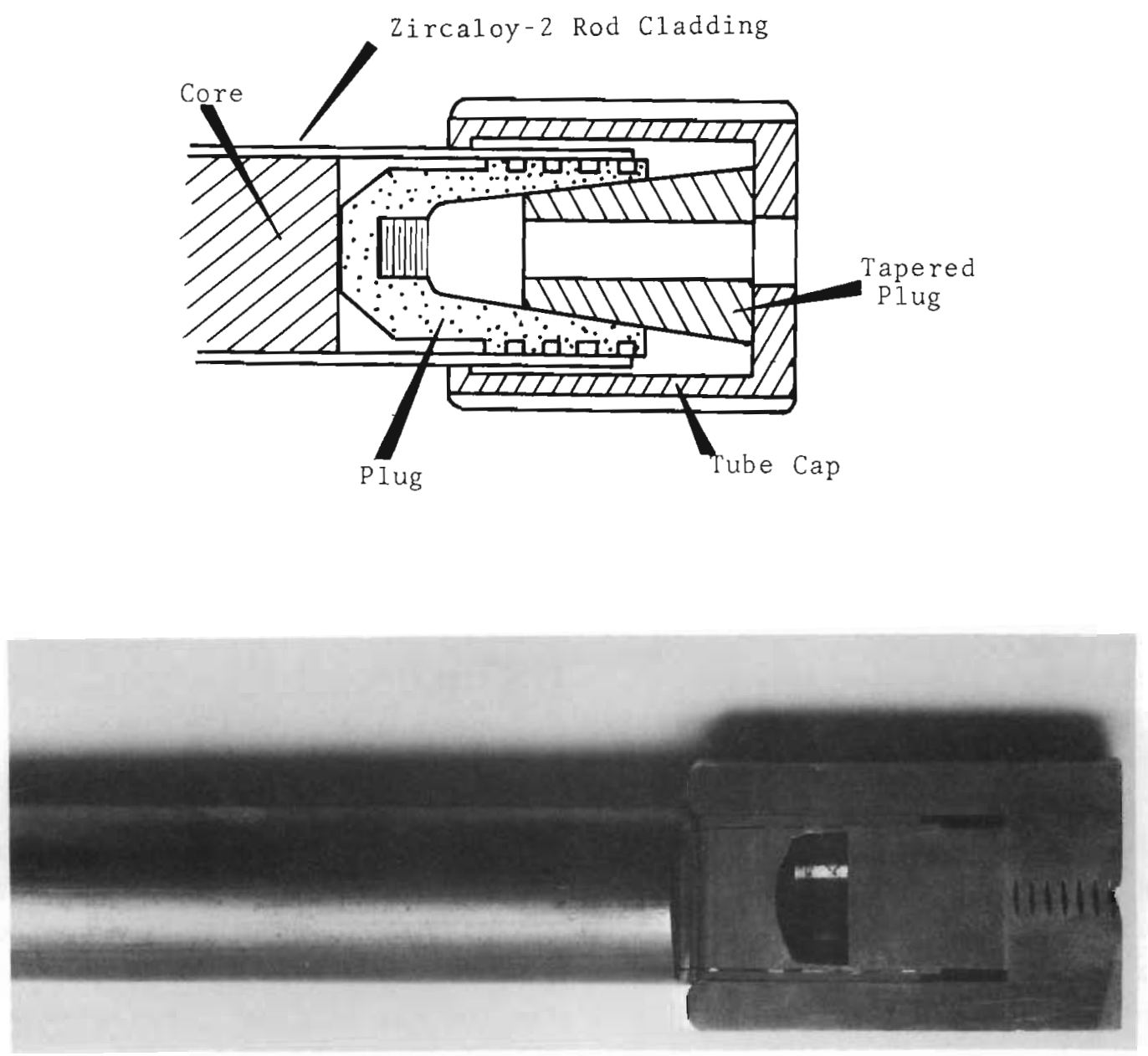
$\mathrm{UO}_{2}-1 / 2$ wt: $\mathrm{PuO}_{2}$ prepared by physical mixture. One was compacted vibrationally and the other by swaging. $(2,3)$ The third and fourth tests used fue 1 rods irradiated to 1890 and $224 \mathrm{MWd} /$ ton, having mixed oxide cores of $\mathrm{UO}_{2}$ 1 wt: $\mathrm{PuO}_{2}$, prepared by Nupac, and compacted by vibration and swaging. The fifth test used a fuel rod with a mixed oxide core containing $\mathrm{UO}_{2}$ 2 wt: $\mathrm{PuO}_{2}$, prepared by Nupac, and Vipac compacted. This rod was packed to $9.39 \mathrm{~g} / \mathrm{cm}^{3}$ or $85.6 \%$ of theoretical density. The core fuel particle size consisted of $55 \%-6+10,12.5 \%-$ $20+35,12.5 \%-35+65$, and $20 \%-$ 200 mesh sizes. The mesh sizes of $\mathrm{UO}_{2}$ used in the other Vipac rods was $65 \%+$ $6+10,20 \%-20+60$, and $15 \%-200$. The swaged rod had $\mathrm{UO}_{2}$ particle sizes of $50 \%-20+65,30 \%-65+200$ and $20 \%$ - 200. Generally, the $\mathrm{PuO}_{2}$ used in all rods was -325 mesh. The theoretical density of the Vipac rods was greater than $85 \%$; the swage rods were 87 to $90 \%$ of theoretical density.

\section{EXPERIMENTAL PROCEDURES}

The following procedures were used for testing the elements. After defecting the elements in Radiometallurgy, they were weighed, photographed, and sent to 242-BAL Building where they were unloaded under water and loaded into the IRP cask. The cask was connected to the loop, and both cask and loop were flushed and filled with demineralized water adjusted to a $\mathrm{pH}$ of 10 with $\mathrm{LiOH}$. The 100 p water was then heated to $300{ }^{\circ} \mathrm{C}$, an average nominal surface temperature of the zircaloy-2 cladding in-reactor, and the water flow maintained at 13 fps past the test element. A standard cycle was used on all tests. This cycle consisted of reducing the loop temperature from 300 to $40{ }^{\circ} \mathrm{C}$ and back after $1,3,7,14$ and 24 days operation to simulate reactor shutdowns. Starting with the fourth test, the loop was also thermal cycled from 300 to $270{ }^{\circ} \mathrm{C}$ and back every $3 \mathrm{hr}$ to simulate unsteady power operation. After completing the fourth test, the test section was vibrated from 36 to $96 \mathrm{cps}$ to approach the vibration of a PRTR process tube which has a $16.5 \mathrm{cps}$ first mode, $51.6 \mathrm{cps}$ second frequency, and about $120 \mathrm{cps}$ third mode. (4) The fue 1 rod in the fifth test was not subject to induced vibration since the test section was vibrating, (due to the flowing water) at a desired frequency and amplitude.

Radiation detection probes, located near the filter, were used to monitor the core release during a test. Frequent discharges and weight measurements were made with the unirradiated fuel element to determine core loss during the test.

\section{EXPERIMENTAL RESULTS}

Test Number 1

The first rod tested was from a section of fuel element No. 5119, a Vipacphysical mixture, $\mathrm{UO}_{2}-1 / 2 \mathrm{wt} \% \mathrm{PuO}_{2}$ core irradiated to about $5000 \mathrm{MWd} / \mathrm{ton}$. The rod was originally defected with a slit $11 / 2$ in. long by $1 / 16$ in. wide (Figure 3a). Some filter activity increase $(80 \mathrm{mR} / \mathrm{hr})$ was noted during the 3 hr heating period to reach $300{ }^{\circ} \mathrm{C}$ 
and during the first day up a total of $280 \mathrm{mR} / \mathrm{hr}$. No further increase was noted during the $31 / 2$ week period comprising the remainder of the test. Weight measurements under water, both before and after the test, failed to show any weight loss; in fact, a weight increase was noted which was probably caused by water logging. A picture of the element after testing is shown in Figure $3 b$.

Because of the absence of significant washout with the $11 / 2 \mathrm{in}$. long slit, it was decided to increase the slit 1 ength to $6 \mathrm{in}$. and rerun the element. The element was returned to Radiometallurgy, and the original slit was in- corporated into the 6 in. long slit. When testing was resumed in the IRP, an activity increase of $100 \mathrm{mR} / \mathrm{hr}$ was detected during the first $3 \mathrm{hr}$, when the water was being heated to $300{ }^{\circ} \mathrm{C}$. Neither constant temperature operation or thermal cycling during the $31 / 2$ week test caused additional activity release. Weight measurements showed $1 \mathrm{~g}$ had been lost from the fuel element. (Figure 4)

It can be estimated from the activity-weight loss relationship from the second part of the test that about $3 \mathrm{~g}$ was lost during the first part of the test.

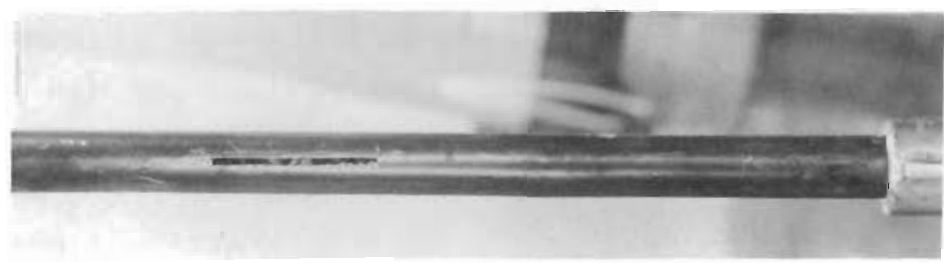

(a) Before Testing

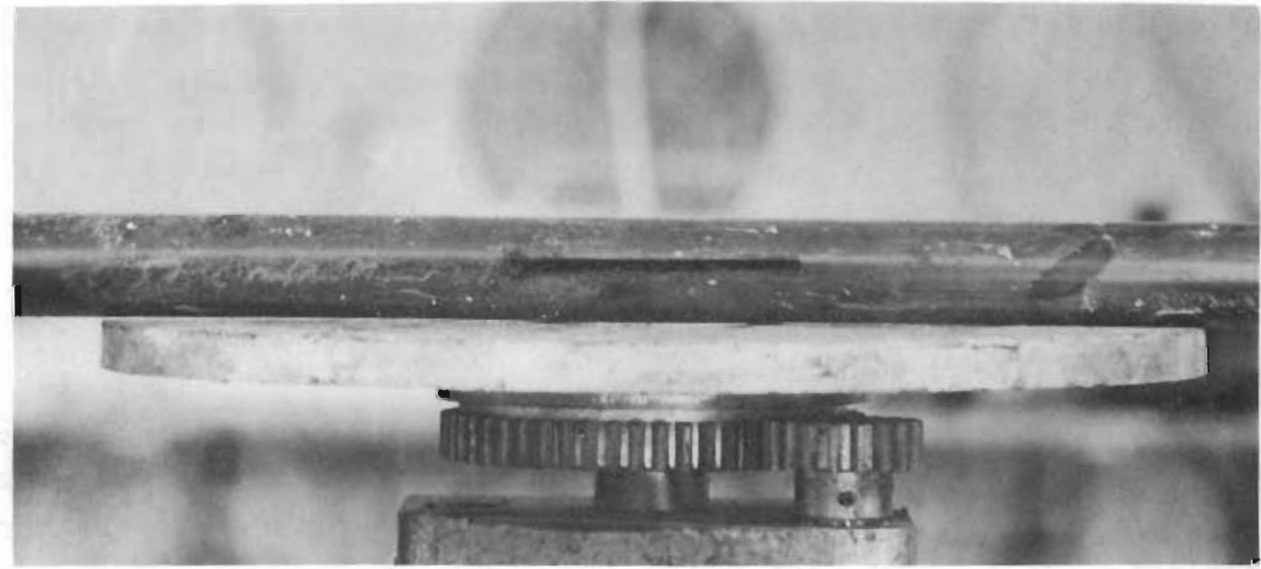

(b) After Testing 


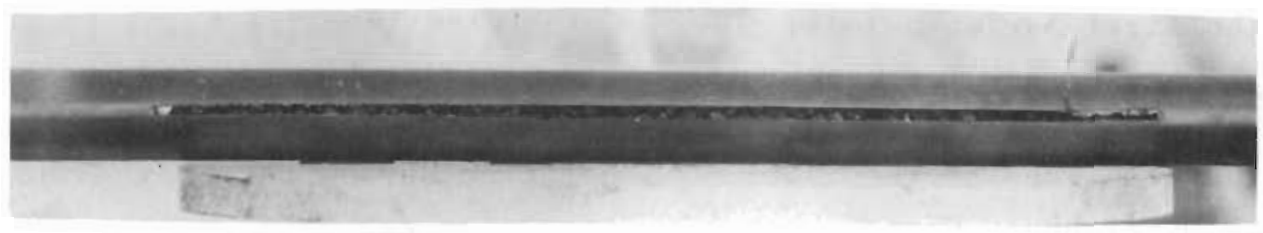

(a) Before Testing

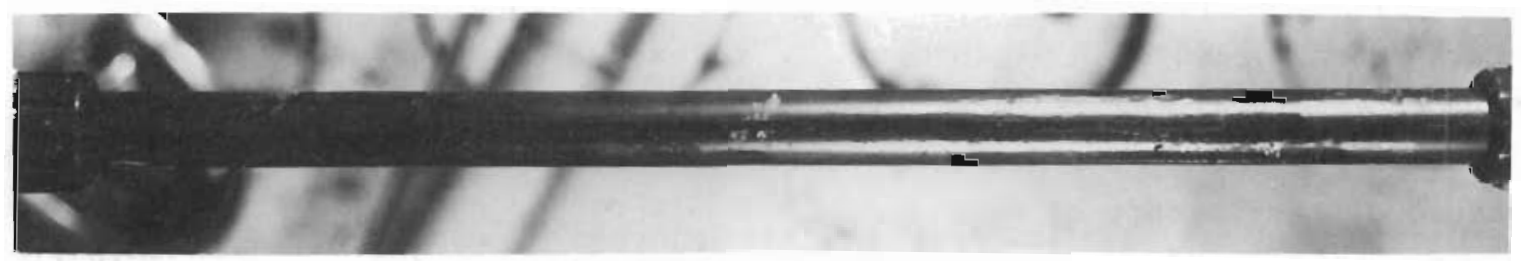

(b) After Testing

FIGURE 4. Fuel Rod No. 5119, Vipac-

Physical Mixture, Before and After

Testing in IRP

Test Number 2

The second rod was from a section of fuel element No. 5164, which had a swaged-physical mixture core containing $\mathrm{UO}_{2}-1 / 2$ wto $\mathrm{PuO}_{2}$ irradiated to about $4100 \mathrm{MWd} / \mathrm{ton}$. The essential difference between this test and the preceding test was the method of final fabrication (swaged versus Nupac).

Testing in the IRP for the $31 / 2$ week period at $300{ }^{\circ} \mathrm{C}, 13 \mathrm{fps}$, and 1600 psi resulted in an extremely small amount of release of core material. Filter activity readings increased only $25 \mathrm{mR} / \mathrm{hr}$. This occurred during the first $2 \mathrm{hr}$ (the heating period) of the test, and did not show any change after that time even during thermal cycling. Pictures of the fuel rod before and after testing (Figure 5) show the core material has not been washed out. Weight measurements of the element did not indicate any core loss; this swaged rod released a smaller amount of activity to the IRP loop system than did the Vipac element. The possible reasons can be seen by comparing Figures 4 and 5 . The Vipac element (Figure 4) has a core with a great deal of void area between granules, which would make it easier to wash out any loose fine core material, while the swaged rod (Figure 5) appears to have a more compact ceramic core with less surface area exposed to the water.

\section{Test Number 3}

Rods used in Tests 3 and 4 were intended to differ from those used in Tests 1 and 2 only by having the core material prepared by the Nupac process rather than by physical mixture. The actual rods tested differed also by having core material containing 1 wt\% $\mathrm{PuO}_{2}$, and lower in-reactor exposures than those previously tested. The 


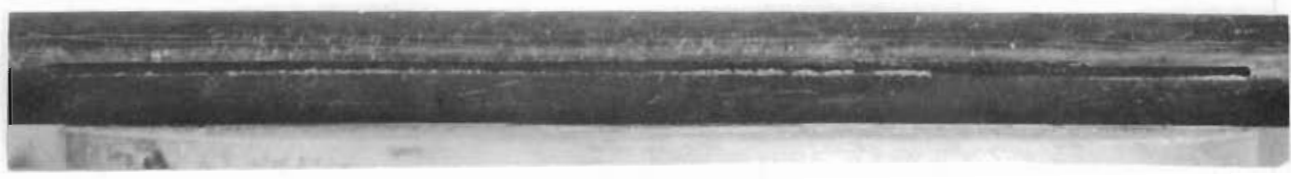

(a) Before Testing

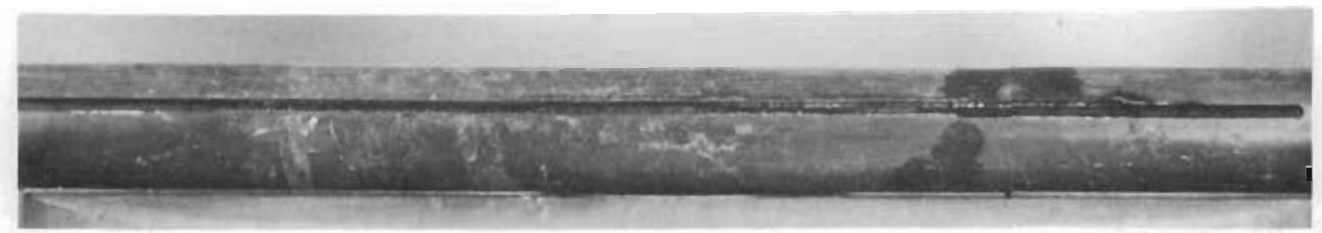

(b) After Testing

EIGURE 5. Fuel Rod No. 5164, SwagedPhysical Mixture, Before and After Testing in IRP

rod used for Test 3 was part of fuel element No. 5233, which was exposed for about $1890 \mathrm{MWd} /$ ton in the PRTR. The $\mathrm{UO}_{2}-1$ wt: $\mathrm{PuO}_{2}$ core was compacted by the Vipac process. The defect was again $6 \mathrm{in}$. long by $1 / 16 \mathrm{in.} \mathrm{wide.}$

As detected by filter activity increase, IRP testing caused some core loss primarily during the initial heating of the loop water and during the next two thermal cycles. The reason for core release during thermal cycling (while somewhat uncertain) was most likely associated with (1) contractions and expansions of core material and cladding which could release fine material, and (2) differences in the properties of the water. A total of $250 \mathrm{mR} / \mathrm{hr}$ was released during the first three thermal cycles (Figure 6). Later thermal cycles failed to release more activity. Comparisons of pictures of the rod (Figure 7) before and after testing show that part of the core, next to the defect, had been washed out during testing. Weight measurements showed
$7 \mathrm{~g}$ were missing as a result of the test.

\section{Test Number 4}

This fuel rod was from element No. 5203, fabricated by swage-Nupac with a $\mathrm{UO}_{2}$ - 1 wt\% $\mathrm{PuO}_{2}$ core, and irradiated to $224 \mathrm{MWd} /$ ton in the PRTR. In addition to the standard temperature cycles from 300 to $40{ }^{\circ} \mathrm{C}$, additional cycling from 300 to $270{ }^{\circ} \mathrm{C}$ every $3 \mathrm{hr}$ was initiated to simulate unsteady power operation. IRP testing failed to release any core material during two weeks of testing, including three temperature cycles to $40{ }^{\circ} \mathrm{C}$. Weightloss measurements in air did not show any loss. Since previous elements had released activity during the first part of the tests only, it was decided to terminate this particular test and to start vibration of the test section at near PRTR conditions. Because the fuel element was not too radioactive (could be handled by use of long tongs), it was removed from the lead filled 


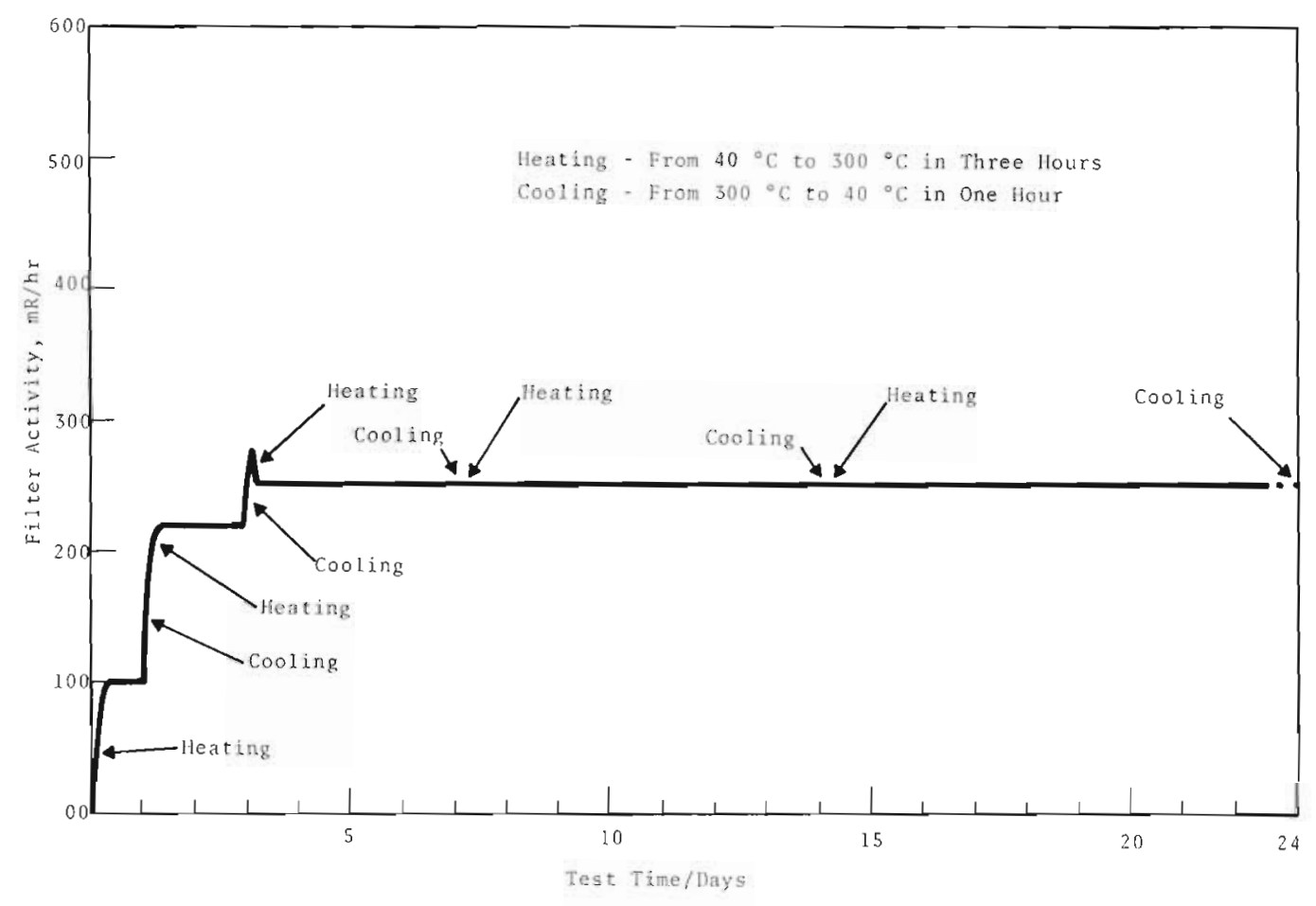

EIGURE 6. Activity Release from Fue?

Rod No. 5233 , Vipac-Nupac During

Testing in IRP

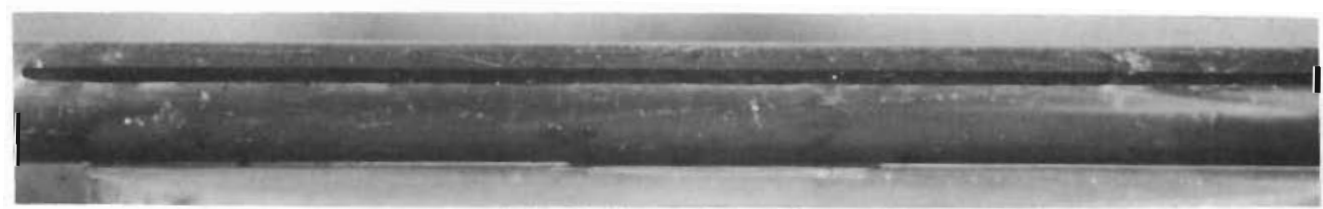

(a) Before Testing

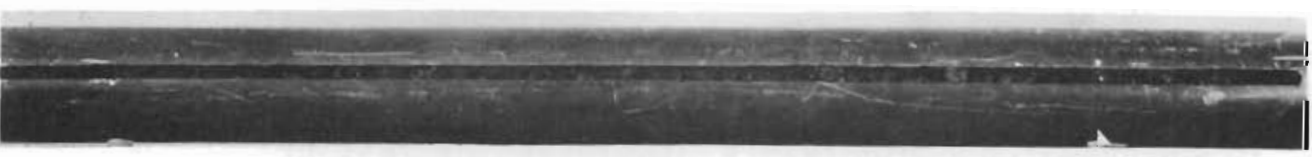

(b) After Testing

EIGURE ?. Euel Rod No. 5233, Vipac-

Nupac, Before and After Testing in IRP

cask and placed in another unshielded vertical test section to allow easier induced vibration. After four days testing with external vibration, the element lost $38 \mathrm{~g}$. The vibrations consisted of one day at each of the following conditions:

\begin{tabular}{|c|c|c|c|}
\hline $\begin{array}{l}\text { Frequency } \\
\begin{array}{c}\text { (cycles } \\
\text { sec) }\end{array}\end{array}$ & 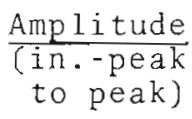 & $\frac{\text { Acceleration }}{\left(\mathrm{g}^{\prime} \mathrm{s} 2 \mathrm{32.2 \textrm {ft }} /\right.}$ & $\frac{\text { velocity }}{(\text { in. }}$ \\
\hline 36 & 0.0014 & 0.09 & 0.16 \\
\hline 55 & 0.0013 & 0.26 & 0.23 \\
\hline 75 & 0.0009 & 0.26 & 0.21 \\
\hline 96 & 0.0021 & 0.95 & 0.65 \\
\hline
\end{tabular}


An additional three days testing at 55 cycles/sec with a 0.0013 peak-topeak amplitude resulted in an additional $27.5 \mathrm{~g}$ loss from the element. The core washout can be seen by comparison of the rod during various stages of testing (Figure 8). It appears quite significant that core loss was noted only when vibration was applied to the system.
Test Number 5

An unirradiated section of a high power density fuel rod used for this test had a core of $\mathrm{UO}_{2}-2$ wt\% $\mathrm{PuO}_{2}$ fabricated by Vipac-Nupac. Because activity measurements could not be used to determine core washout for this test, the element was discharged from the test section and weighed

(a)

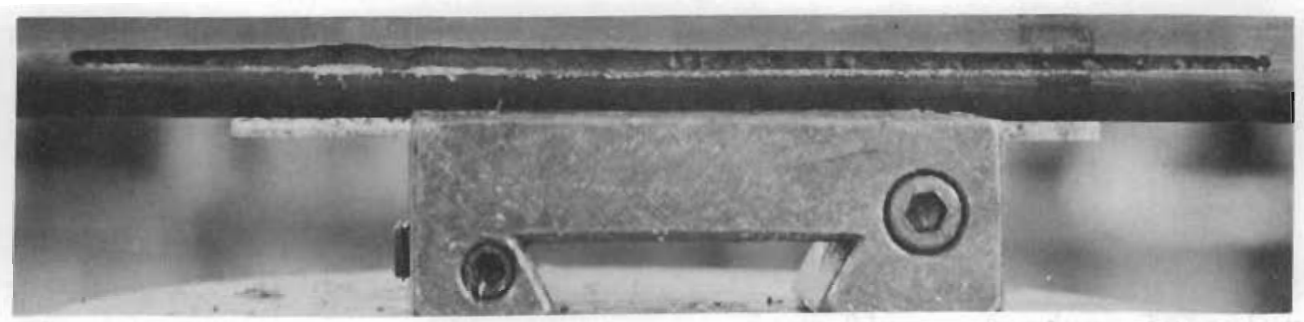

(b)

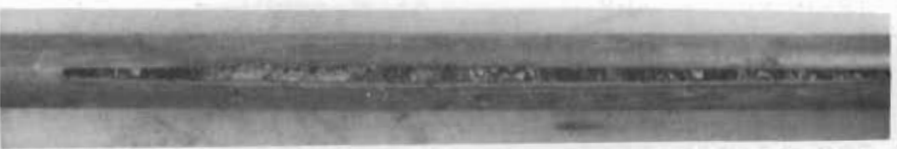

(c)

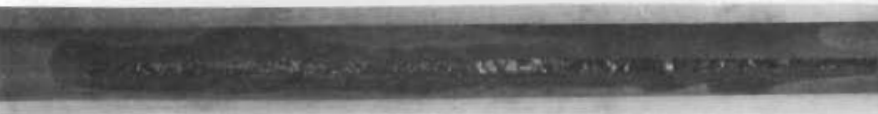

(d)

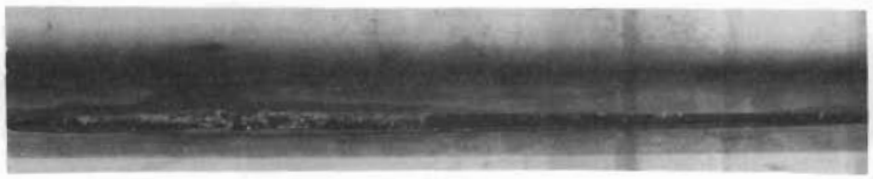

FIGURE 8. Fuel Rod No. 5203, Swage-

Nupac, (a) Before Testing, (b) Before

Vibration, (c) After first Vibration

Period, (d) After second Vibration

Period 
during some of the cooling cycles. The temperature in the loop was cycled to $270{ }^{\circ} \mathrm{C}$ every $3 \mathrm{hr}$ in addition to the four cycles to $40{ }^{\circ} \mathrm{C}$. It was intended to externally vibrate the test section, but vibration measurements showed considerable vibration already present $(55$ cycles/sec at a 0.0005 in. peak-to-peak displacement); no further induced vibration was used. After seven days testing, the element lost $59 \mathrm{~g}$ of core material; after 14 days the total was $77 \mathrm{~g}$ Ioss; and after 24 days, the total loss was $86 \mathrm{~g}$. The entire core weight prior to testing was $35 \mathrm{Ig}$, so about $25 \%$ of the core was washed out. Pictures of the rod after testing (Figure 9) strikingly resemble the other Vipac fabricated, irradiated elements (Figures 3 and 6). Large granules of perhaps $-6+10$ mesh material, of which $55 \%$ of the core was composed, can be seen under the slit. It appears that the fine material around the larger granules has been washed away, leaving the larger particles. Had defect opening been larger than the largest particle used in the core, more of the core probably would have been washed out.

\section{DISCUSSION OF RESULTS}

The IRP tests are out-of-reactor tests with previously irradiated fuel elements. It is questionable whether the results obtained in out-of-reactor tests can be used to predict pattern of failure in a reactor under actual operation. This could be resolved by testing identical elements both in-reactor and out-of-reactor to compare results. Obviously, several large differences exist between power producing elements and isothermal out-ofreactor elements in terms of core temperatures, thermal gradients, and results of water penetration through defects in the cladding. In-reactor fuel elements would probably produce some steam from the water that had access to the core. The formation of steam could create considerably more core washout (depending on where it was being formed), or it could cause less washout if it blocked off water which could physically wash out part of a cracked and loose core. The overa11 effect of temperature differences when comparing in-reactor and out-ofreactor tests is still undecided.

The size of the defect used in the out-of-reactor tests, 6 in. long by $1 / 16$ in. wide was thought to be the worst condition that could occur inreactor, but the recent failure in the PRTR FERTF propduced a defect that was considerably worse than those used in the out-of-reactor tests. That defect was the full width of

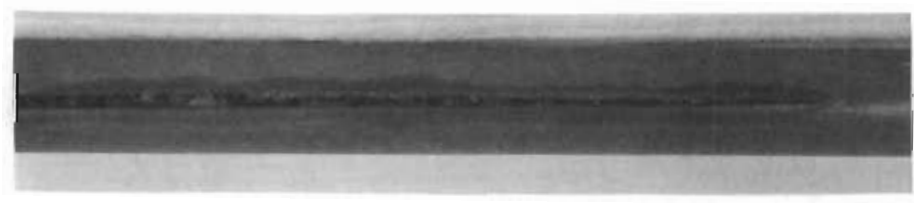

FIGURE 9. Unirradiated Short Core Element, $\mathrm{UO}_{2} \mathrm{~L}^{2}$ wt\% $\mathrm{UO}_{2}$ Core, After resting in IRP 
the fuel rod $(0.6 \mathrm{in.})$ in places and extended to 3 in. in length; however, the artifical slit defect at least seems to be in the right prospective of size.

other conditions in the out-ofreactor tests, including water temperature, flow velocity, water pH and conductivity, loop pressure, fuel material, and operating times, were designed to duplicate in-reactor conditions.

Even though differences do exist between in-reactor and out-of-reactor washout tests, out-of-reactor tests may produce results very similar to inreactor tests. Several washout tests have been run in the FERTF with swaged and vibrationally compacted $\mathrm{UO}_{2}$ core elements that were defected with longitudinal slits. (5) The first FERTF washout test used a swaged element preirradiated to $2440 \mathrm{MWd} / \mathrm{ton}$; it showed no evidence of swelling, negligent washout, and no water logging after 23 days operation, including 3 pressurizations and 10 power cycles. The element was originally defected with a 0.63 in. long slit which was later increased to 3 in. A second swage compacted $\mathrm{UO}_{2}$ element defected with a 6.5 in. long slit operated for 16 days with no evidence of fuel washout, water logging, or fuel rod swelling visible under water. The element was preirradiated to $3270 \mathrm{MWd} / \mathrm{t}$ on and was operated at a maximum tube power of $1157 \mathrm{~kW}$. There were no activity bursts in either element during power level increases, and steady state activity release rates showed a strong power dependence. A determination of fission product ratios in the coolant established the release mode to be primarily

diffusion. (6)

A vibrationally-compacted $\mathrm{UO}_{2}$ element preirradiated to $1770 \mathrm{MWd} / \mathrm{ton}$ with a 3 in. long slit was tested for 22 days in the FERTF. Underwater examination in the PRTR basin after exposure showed no evidence of fuel washout, waterlogging, or of fue 1 rod swelling. The slit width had increased, however, from 0.02 in. to 0.05 in. at the widest point. The steady state activity release was more than from a correspondingly long sit in the swaged rods, and indicated that fission gas release is greater from vibrationally-compacted elements, apparently because of the lower bulk density. (5) The slit in this element was increased to a total length of 4 in., and it was reirradiated in the FERTF for an additiona 18 days. Again, no evidence of fuel washout, waterlogging, or of fuel swelling was noted. The steady state activity release rate during this time was comparable to the release rate from the 6.5 in. long slit in the swaged element.

The out-of-reactor IRP tests showed the swage-compacted elements to be more resistant to washout than the vibrationa $11 y$-compacted elements. The swage-compacted elements used in Tests 2 and 4 showed no weight loss until external vibration was used. The vibrationally compacted elements used in Tests 1 and 3 gave weight losses of 1 to $4 \mathrm{~g}$ and $7 \mathrm{~g}$, respectively. These weight losses in out-of-reactor tests are difficult to understand when a similar element in the FERTF apparently experienced no washout. Visual exam- 
IRP test element (Figure 7) shows that considerably more than $7 \mathrm{~g}$ could have been washed out. Two other differences that may have contributed to higher losses in the IRP were the use of a mixed oxide core $\left(\mathrm{UO}_{2}-\mathrm{PuO}_{2}\right)$ rather than straight $\mathrm{UO}_{2}$ and the use of a wider slit in IRP tests $(0.065$ in. rather than 0.02 in.). The core (Figure 7) appears to have most of the fines removed, (leaving the larger mesh particles) but whether they have been removed from the outer circumference all the way around the element or just under the slit is not known. The swaged elements from Tests 2 and 4 have a core with a more uniform appearance, and the fines were seemingly in place before the applied external vibrations. In both the IRP and FERTF tests with swaged elements, the core is not washed out.

The relative importance of the amount of vibration, which may exist in the system, should not be overlooked. IRP tests with induced vibrations up to amplitudes of $0.002 \mathrm{in}$. and frequencies up to 96 cycles/sec caused very substantial core washout of a swaged core that had not released any core until vibrations were applied. The unirradiated element used in Test 5 had a slightly smaller end fitting (to give a larger flow annulus) on the downstream end to prevent large particle wedging between the end fitting and test section pipe. This difference in end fitting size apparently allowed the test element to vibrate, with substantial core loss as a result.

None of the tests in the IRP indicated further oxidation of the core to some higher oxide. No color change of the core or no clad swelling was visually detected. Analytical procedures were not used to confirm oxidation to a higher state.

\section{FUTURE TESTS}

The future planned program for evaluation of ceramic core washout studies involves testing of a large number of both irradiated and unirradiated fuel samples to determine if some fuels are more resistant to washout than others, and to determine the needed changes for improving washout resistance.

One test that should be performed involves an irradiated pelletized core fuel element for comparison with the unsintered starting core material used in the PRTR. Since the majority of U.S. Reactors have used pelletized $\mathrm{UO}_{2}$, this fuel type might be used as a base for comparing washout tests.

The effect of $\mathrm{PuO}_{2}$ addition to the $\mathrm{UO}_{2}$ must be evaluated with irradiated elements, including $\mathrm{PuO}_{2}$ contents of 2 and 4 wt\%. Swaged and vibration compacted $\mathrm{UO}_{2}$ core elements should be tested for comparison with $\mathrm{PuO}_{2}$ additions to the core. Material from new fuel processes, such as the salt cycle process for reclaiming the $\mathrm{PuO}_{2}$ in an irradiated element, should be evaluated. New types of elements to be tested include:

- EBWR rods

- Wire enriched rods

- Thoria-PuO 2 core rods

- Water tube test element.

The studies could be augmented by 
including test rods irradiated at rod powers more typical of current and future power reactors, and which are greater than those now reached in the PRTR.

The above fuel types (and others) should also be tested with unirradiated rods. Testing would determine effect of fabrication variables such as

- Particle sizes

- Particle shape

- Oxygen to uranium ratio

- Particle density

- Particle size distribution

- Vibration frequency.

Several unirradiated rods could be tested at the same time to reduce the time required. Initia11y, most tests would be run without external vibration; however, to determine vibration resistance, vibrations might be applied during the latter part of the test.

For better understanding of the comparison of IRP tests and FERTF tests, similar irradiated and defected test specimens should be run in both the FERTF and the IRP at nearly identica 1 conditions. Possibly, special Vipac elements with mixed oxide cores could be fabricated and irradiated for this purpose. The rods could be irradiated together and the same device used for defecting both elements. The same temperature and pressure cycling would be used in each, and water samples would be taken to compare radioisotopes in each system.

The addition of a second loop at 242-B for washout studies of unirradiated fuel rods has been started.
This should greatly increase the quantity of fuel rods tested.

\section{ACKNOWLEDGEMENTS}

The author is grateful to C. H. Allen and $J$. J. Hauth for supplying the test rods; N. D. Stice for operation of the test 1oop; and W. J. Gruber for examination of the fuel rods.

\section{REFERENCES}

1. G. E. Neibaur and N. D. Stice. The Irradiated Slug Rupture Prototype (IRP) Design, HW-52701. General EZectric Co. Richland, Wash. February 15, 1960.

2. Specifications for Vibrationalzy Compacted, Mixed Oxide (UO $-\mathrm{PuO}_{2}$ ) Fuel Elements for the PRTR (Mark 1-L), HW-79291. General Electric Co., Richland, Washington.

october 1, 1963.

3. Specifications for swage Compacted, Mixed Oxide (UO 2-PuO 2 ) Fuel Elements for the PRTR (Mark $1-\bar{M})$, $\overline{H W}-79290$. General Electric Co., Richland, Washington. October 1, 1963.

4. W. C. Townsend. Unpublished data, Nov. 1965, Richland, Washington, $B N W$.

5. Ceramics Research and Development Operation Quarterly Report, January - March, 1965, edited by D. R. deHalas, BNWL-91.

6. Ceramics Research and Development operation Quarterly Report, October - December, 1964, edited by D. R. deHalas, $H W-81603$. General Electric Company, Richland, Wash. 

,

.

. 


\section{DISTRIBUTION}

Number

of Copies

\section{Division of Technical Informa- tion Extension}

5 Douglas United Nuclear, Inc.

T. W. Ambrose

T. W. Evans

L. E. Kusler

E. A. Smith

J. J. Stringer

1 General Electric Company, Pleasanton

E. A. Evans

1 Genera1 Electric Company, San Jose

E. L. Zebroski

3 Richland Operations office

P. G. Holsted

R. K. Sharp

Technical Information Library

45

Battelle-Northwest

F. W. Albaugh

C. H. Allen

H. J. Anderson

J. A. Ayres

J. M. Batch

S. H. Bush

J. J. Cadwe 11

G. M. Dalen

D. R. DeHalas

R. L. Dillon
Battelle-Northwest (contd)

K. Drumheller

J. R. Fishbaugher

J. C. FoX

M. D. Fresh1ey

S. Goldsmith

W. J. Gruber

W. L. Hampson

L. A. Hartcorn

H. Harty

J. J. Hauth

K. D. Hayden (10)

D. L. Hovorka

G. A. Last

W. R. Lewis

R. J. Lobsinger

J. E. Minor

L. D. Perrigo

W. D. Richmond

W. E. Roake

D. P. Schively

D. W. Shannon

R. E. Skavdah 1

V. H. Troutner

M. T. Walling

R. D. Weed

O. J. Wick

W. K. Winegardner

F. W. Woodfield Technical Information Library (5)

Technical Publications 
